\title{
ESTUDO DA QUALIDADE DA ÁGUA DO CÓRREGO DOS MACACOS, MUNICÍPIO DE ÁLVARES MACHADO/SP
}

\author{
Bruna de Souza Silva ${ }^{1}$
}

\author{
Renata Ribeiro de Araujo ${ }^{2}$
}

\begin{abstract}
RESUMO
A interferência humana na natureza vem provocando significativas alterações na qualidade da água dos córregos. Neste sentido, a presente pesquisa teve por objetivo realizar o monitoramento limnológico em seções do córrego dos Macacos, localizadas no município de Álvares Machado/SP, a fim de compreender o comportamento de variáveis físicas, químicas e biológicas. Para isto, foram feitas amostragens em cinco seções do córrego. As variáveis avaliadas foram temperatura da água $(T)$, condutividade elétrica (CE), turbidez (Turb), $\mathrm{pH}$, oxigênio dissolvido (OD) e nitrato através de uma multisonda paramétrica de marca Hanna modelo HI9829. Os resultados do monitoramento apontaram para uma má qualidade da água do córrego, atribuída à interferência humana, ou seja, uso e cobertura da bacia hidrográfica.
\end{abstract}

PALAVRAS-CHAVE: Monitoramento limnológico. Córrego dos Macacos. Álvares Machado.

\section{STUDY OF THE WATER QUALITY OF MACACOS STREAM, MUNICIPALITY OF ALVARES MACHADO/SP}

\begin{abstract}
The human interference in nature has led to significant changes in the water quality of streams. In this sense, the present study aimed to realize the limnological monitoring in sections of Macacos stream, located in the municipality of Alvares Machado/SP, in order to understand the behavior of physical, chemical and biological variables. For this, samples were taken in five sections of the stream. The variables evaluated were water temperature (T), electrical conductivity (EC), turbidity (Turb), $\mathrm{pH}$, dissolved oxygen (DO) and nitrate through a parametric Multiprobe brand Hanna model HI9829. Monitoring results pointed to a poor quality of stream water, which was attributed to human interference in the use and coverage of the watershed.
\end{abstract}

KEY-WORDS: Limnological monitoring. Macacos Stream. Alvares Machado.

\footnotetext{
${ }^{1}$ Graduanda em Engenharia Ambiental, Unesp. brunnasouzasilva@hotmail.com.

${ }^{2}$ Doutora, Faculdade de Ciências e Tecnologia - Unesp. reribeiro@fct.unesp.br.
} 


\title{
ESTUDIO DE LA CALIDAD DE LA AGUA DEL ARROYO DE LOS MACACOS, MUNICIPIO DE ALVARES MACHADO/SP
}

\begin{abstract}
RESUMEN
La intervención humana en la naturaleza ha dado lugar a cambios significativos en la calidad del agua de los arroyos. En este sentido, el presente estudio tuvo como objetivo realizar el monitoreo limnológico en las secciones del arroyo de los Macacos, que se encuentra en el municipio de Alvares Machado/SP, con el fin de comprender el comportamiento de las variables físicas, químicas y biológicas. Para ello, se tomaron muestras en cinco secciones del arroyo. Las variables evaluadas fueron la temperatura del agua (T), conductividad eléctrica (CE), la turbidez (Turb), pH, oxígeno disuelto (OD) y nitrato a través de una multisonda paramétrica de marca Hanna modelo HI9829. Los resultados del monitoreo apuntaron a la mala calidad de la agua del arroyo, lo cual se atribuye a la interferencia humana en el uso y cobertura de la cuenca.
\end{abstract}

PALABRAS-CLAVE: Monitoreo limnológico. Arroyo de los Macacos. Alvares Machado 


\section{INTRODUÇÃO}

Todos os ecossistemas aquáticos continentais estão submetidos a um conjunto de impactos resultantes das atividades humanas e dos usos múltiplos das bacias hidrográficas (TUNDISI; MATSUMURA, 2008). Com a crescente expansão urbana nota-se algumas mudanças tanto no ciclo hidrológico quanto na qualidade da água.

Tais interferências vêm trazendo consequências tanto para a natureza quanto para o próprio homem. Com o aumento da urbanização e com o uso de produtos químicos na agricultura e no ambiente em geral, a água utilizada nas cidades, indústrias e na agricultura retorna contaminada aos rios (ALVES et al., 2008; OLLI et al., 2009).

Outra consequência da presença humana é a retirada de cobertura vegetal, importante na manutenção da qualidade da água. Segundo Oliveira-Filho et al. (1994), a retirada das matas ciliares tem contribuído para o assoreamento dos rios, o aumento da turbidez das águas, o desequilíbrio do regime das cheias, a erosão das margens de grande número de cursos d'água, além do comprometimento da fauna silvestre.

A impermeabilização do solo também é outro problema que vem contribuindo para o carreamento em maior volume de sedimentos e poluentes para os canais d'água. Uma vez que as ruas apresentam pouca ou nenhuma barreira ao escoamento, as águas tendem a se concentrar rapidamente e seguirem para os sistemas de drenagem, que levam as águas para os locais mais baixos da vertente, os córregos (SCHNEIDER et al., 2011).

Nesse sentido, o monitoramento entra como uma forma de investigação para compreender a magnitude de tais impactos nos córregos urbanos. Os comportamentos de variáveis físicas, químicas e biológicas representam a forma como o corpo d'água responde aos impactos promovidos pelo uso e cobertura da bacia hidrográfica.

O córrego dos Macacos, situado no município de Álvares Machado/SP encontra-se na periferia da malha urbana e o objetivo da presente pesquisa é 


\section{Volume 10, Número 2, 2014 \\ Bacias Hidrográficas, Planejamento e Gestão dos Recursos Hídricos}

investigar como a presença antrópica afeta a qualidade da água do córrego e identificar as possíveis tendências e ou padrões no comportamento espacial das variáveis físicas, químicas e biológicas.

\section{Materiais e Métodos}

O Córrego dos Macacos pertence à Unidade de Gerenciamento Integrado de Recursos Hídricos da Bacia do Aguapeí-Peixe (UGRHI 21), localizando-se no extremo oeste do estado de São Paulo. Suas nascentes situam-se na porção norte do município de Álvares Machado, no baixo curso do Rio do Peixe, e é classificado como classe 2, segundo o Decreto Estadual n 10.755, de 22 de novembro de 1977.

A coleta de amostras para o monitoramento foi realizada no mês de junho de 2014. Foram definidas cinco seções (Figura 1), nas quais foram realizadas amostragens limnológicas ao longo de um trecho córrego.

Figura 1 - Localização das seções amostrais na bacia hidrográfica do córrego dos Macacos.

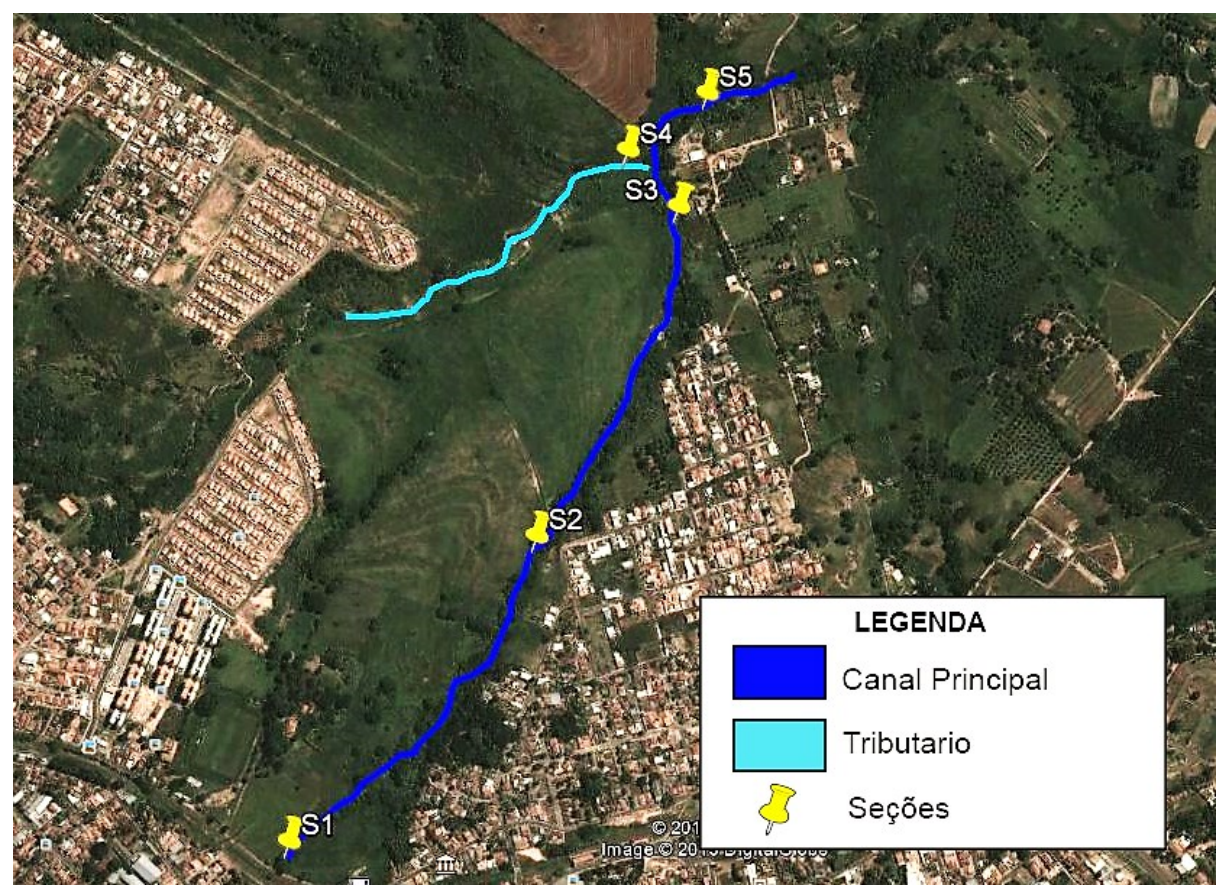

Fonte: Google Earth (2013) 
Em campo, através de uma multisonda paramétrica de marca Hanna modelo HI9829, foram medidos temperatura da água ( $\mathrm{T}$ ), condutividade elétrica (CE), turbidez (Turb), pH, oxigênio dissolvido (OD), e nitrato $\left(\mathrm{N}^{-\mathrm{NO}_{3}}\right)$.

Para o cálculo da vazão foi utilizada a equação 1.Para tanto, foi realizada uma batimetria da seção para obtenção da área, e a velocidade foi determinada utilizandose de um corpo flutuante lançado no corpo d'água e com o cronometro foi contado o tempo no qual este material percorre em $1 \mathrm{~m}$ medido com um trena.

$$
Q=A \cdot V_{m}
$$

Onde,

$Q$ é a vazão $\left(\mathrm{m}^{3} / \mathrm{s}\right)$

A é a área da seção $\left(\mathrm{m}^{2}\right)$

$V_{m}$ é a velocidade média de escoamento $(\mathrm{m} / \mathrm{s})$

Os resultados obtidos durante o monitoramento foram discutidos com base nos valores de referência regulados pela Resolução CONAMA n 357 de 17 de março de 2005 e por recomendações do órgão ambiental do estado de São Paulo, a Companhia de Tecnologia de Saneamento Ambiental (CETESB).

\section{Resultados e Discussão}

Os resultados obtidos durante o monitoramento, com base na Resolução CONAMA $n^{\circ} 357$ de 17 de março de 2005, apresentaram valores em não conformidade para algumas variáveis. Puderam-se notar também tendências espaciais com relação aos valores das variáveis nas diferentes seções amostradas.

Em relação à vazão, os resultados nas seções amostrais do córrego dos Macacos estão apresentados na figura 1. Avaliando-se estes resultados e de acordo com a dimensão longitudinal do canal principal pôde-se observar que entre as seções 1, 2 e 3 não há contribuição de tributários e de efluentes. Entretanto, pôde-se notar através dos resultados um pequeno aumento nos valores entre uma seção e outra. Este fato pode estar relacionado às interações verticais da dinâmica hidrológica, 
ocorridas em sistemas fluviais, associadas aos fluxos subterrâneos e zona hiporrêica. Segundo Boulton et al. (1998) a zona hiporrêica é um ecótono ativo entre o fluxo de águas superficiais e subterrâneas e trocas de água, nutrientes e matéria orgânica ocorrem em resposta a variações na descarga, topografia e porosidade. A ressurgência de subsuperfície abastece a água transportando organismos e nutrientes e o fluxo de subsidência da água fornece oxigênio dissolvido e matéria orgânica aos microrganismos e invertebrados da zona hiporrêica.

Diante deste contexto, provavelmente, entre estas seções o gradiente hidráulico é ascendente, ou seja, o fluxo subterrâneo da zona hiporrêica contribui com o canal fluvial.

Na seção 5, após a chegada do tributário, é perceptível a contribuição da vazão do tributário para o canal principal, como pode ser observado na figura 1. Os valores da vazão na seção 5 são superiores às outras seções.

Figura 1 - Resultados da variável vazão em relação às seções amostrais.

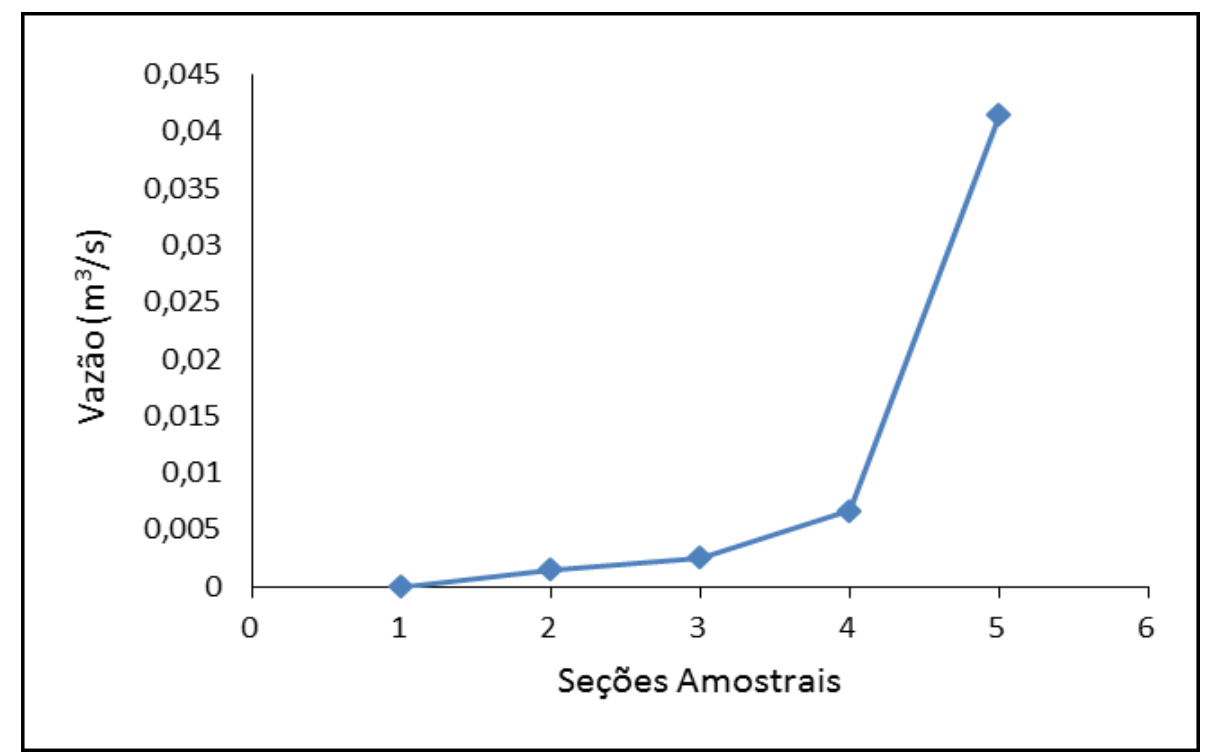

Na Figura 2 se puderam observar os valores da precipitação acumulada em milímetros entre os meses de setembro de 2013 e junho de 2014, no município de Presidente Prudente-SP, município vizinho ao município de Álvares Machado. Notase que a precipitação acumulada é maior durante o verão e menor no inverno. 
No mês em que a coleta foi realizada, junho de 2014, verificou-se que a precipitação acumulada apresentou valor mais baixo em relação aos meses anteriores.

Figura 2 - Resultados mensais da precipitação acumulada no município de Presidente Prudente no intervalo de setembro de 2013 a junho de 2014.

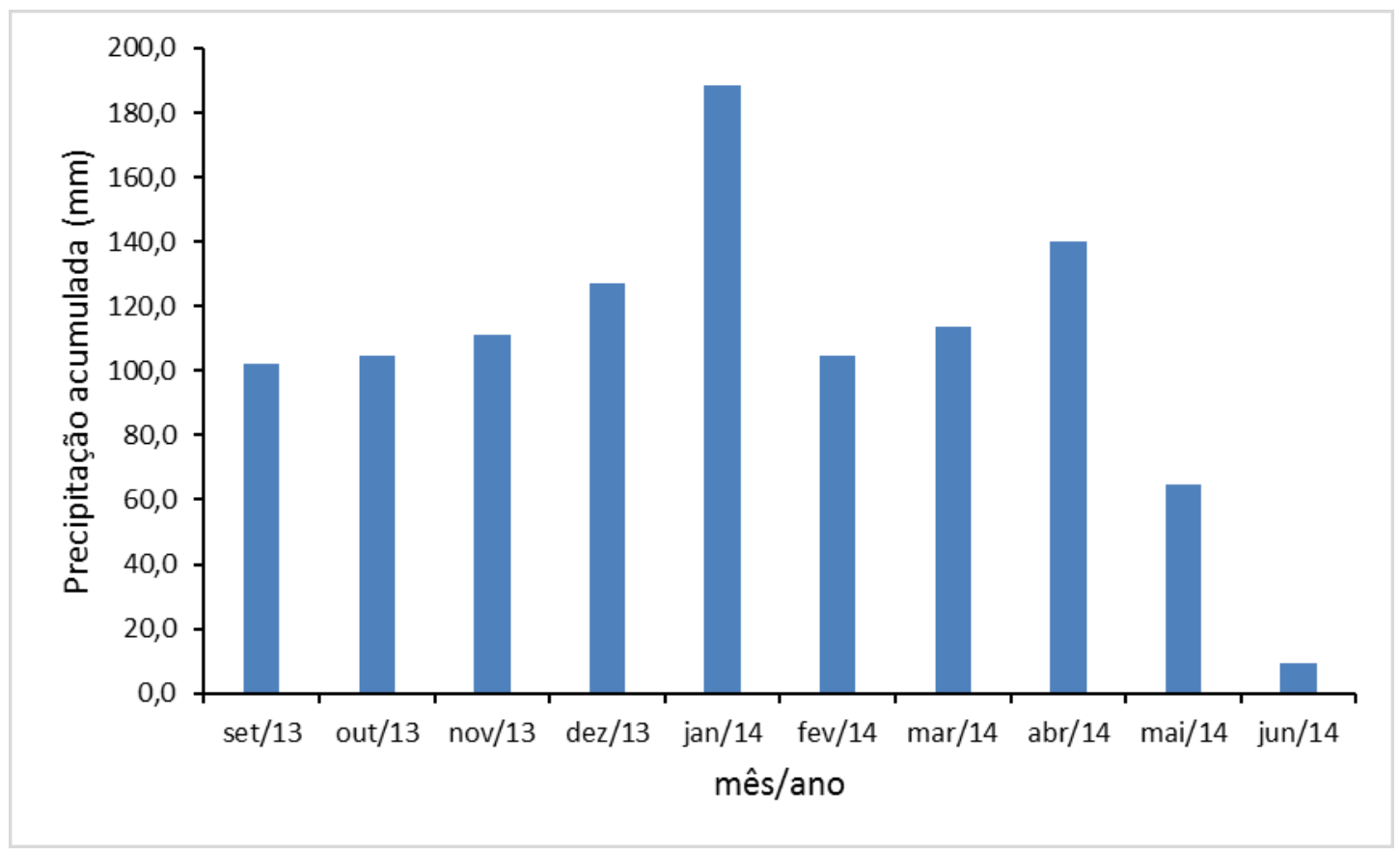

Fonte: Estação Meteorológica - FCT-Unesp (2013/2014)

Estes resultados de precipitação são esperados para a região do oeste paulista. Na região Sudeste e norte da região Sul, o verão costuma ser a estação do ano mais chuvosa, pois esta é a estação que, devido à radiação solar incidente, causa maior impacto nas anomalias de umidade do solo, influenciando na evaporação e, consequentemente, nos fluxos de calor sensível e latente. (MADRUGA; RAO; HADA, 2014)

O regime de chuvas influencia o comportamento das variáveis, sendo uma das principais delas, a temperatura, que por sua vez, influencia outras variáveis (Esteves, 1998; Rocha, 2003).

Além da precipitação, a temperatura da água é influenciada por fatores tais como radiação disponível, latitude, altitude, estação do ano, período do dia, taxa de 
fluxo e profundidade (Zumach, 2003). A ação antrópica, como o despejo de efluentes, também podem contribuir com a elevação da temperatura dos corpos d'água.

A legislação federal reguladora, resolução CONAMA 357/05, não apresenta valores máximos e mínimos de temperatura para corpos d'água. Entretanto, o regime térmico dos corpos d'água na natureza tem grande importância ecológica devido às interações entre a temperatura e a vida aquática (ANGELOCCI e VILLA NOVA, 1995).

A variação nos valores de temperatura entre as seções foi pequena, sendo a máxima $18,8{ }^{\circ} \mathrm{C}$ e a mínima $18{ }^{\circ} \mathrm{C}$. Estes valores baixos estão de acordo com a temperatura média esperada para os meses de inverno no município de Álvares Machado, não demonstrando, portanto, interferência antrópica.

Notou-se uma tendência espacial dos valores da temperatura, havendo diminuição da nascente para a jusante, como pode ser observado na Figura 3.

Figura 3 - Resultados da variável temperatura em relação às seções amostrais.

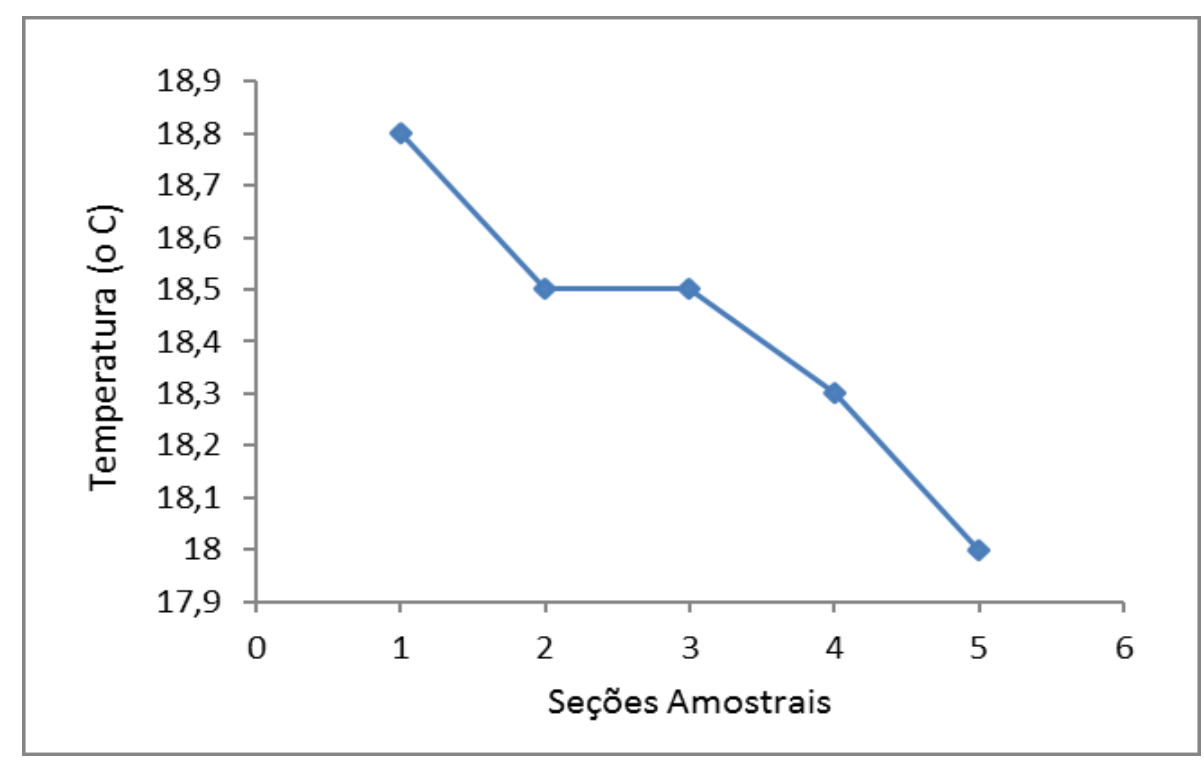

A concentração de oxigênio dissolvido em um corpo d'água é influenciada por diversos fatores. Segundo Fiorucci \& Benedetti-Filho (2005) o oxigênio é inversamente proporcional à temperatura e à salinidade e diretamente proporcional à pressão do meio. 
De fato foram observados maiores valores de oxigênio dissolvido (Figura 4) para menores valores de temperatura, ou seja, inversamente proporcional.

Figura 4 - Resultados de Oxigênio Dissolvido em relação às seções amostrais.

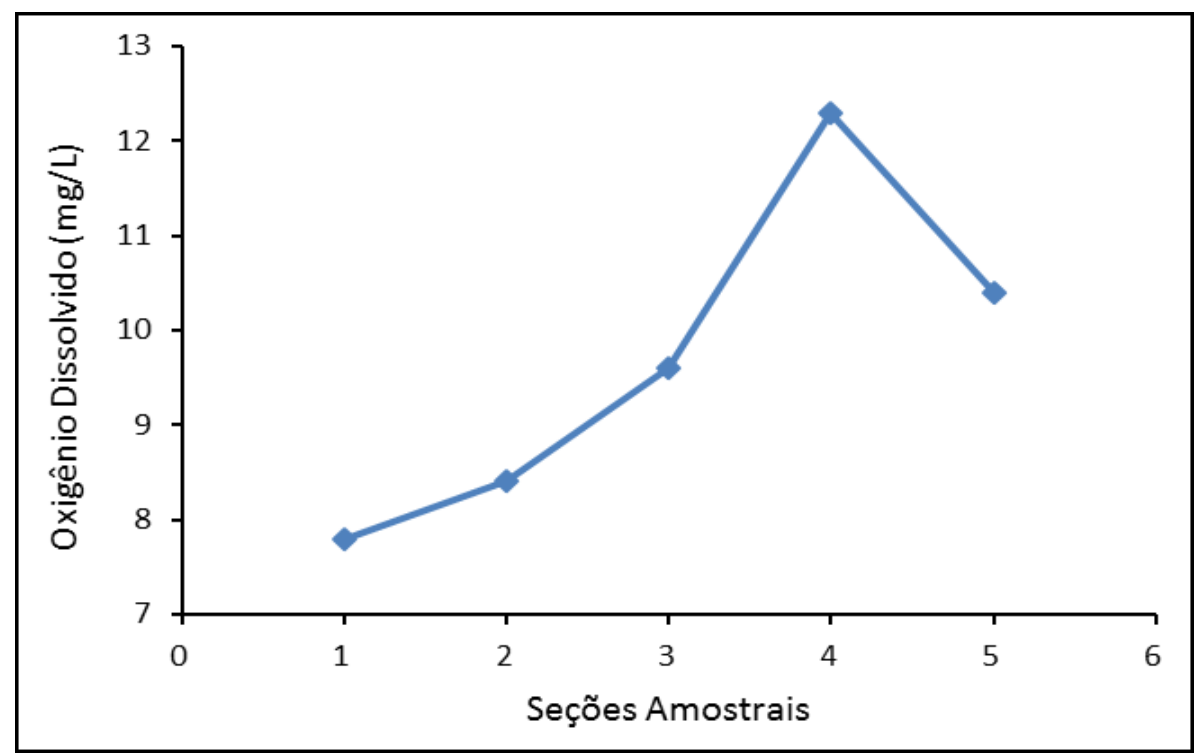

O oxigênio é um elemento essencial no metabolismo dos seres aquáticos aeróbicos. Em águas correntes, sob circunstâncias normais, o conteúdo de oxigênio é alto e varia ao longo do rio, devido a alterações em suas características ambientais e em consequência das condições climáticas (Maier, 1987). A esse respeito, puderamse observar altos valores de oxigênio dissolvido nas seções amostrais, corroborando com Rocha (2003) que diz que a tensão de oxigênio geralmente é alta e mais uniforme em ambientes lóticos. Além disso, verificou-se um aumento dos valores de oxigênio ao longo do canal fluvial.

Segundo a Resolução CONAMA 357/05 os valores de oxigênio dissolvido não devem ser inferiores a $5 \mathrm{mg} / \mathrm{L}$, desta maneira, pôde-se observar que os resultados estão em conformidade com a legislação federal.

$\mathrm{O} \mathrm{pH}$ juntamente com outros parâmetros, pode fornecer indícios do grau de poluição, metabolismo de comunidades ou ainda impactos em um ecossistema aquático. (Zuin et al., 2009). Os resultados de pH (Figura 5) apresentaram-se dentro dos limites estabelecidos pela resolução CONAMA 357/05, isto é, entre 6,0 e 9,0. 


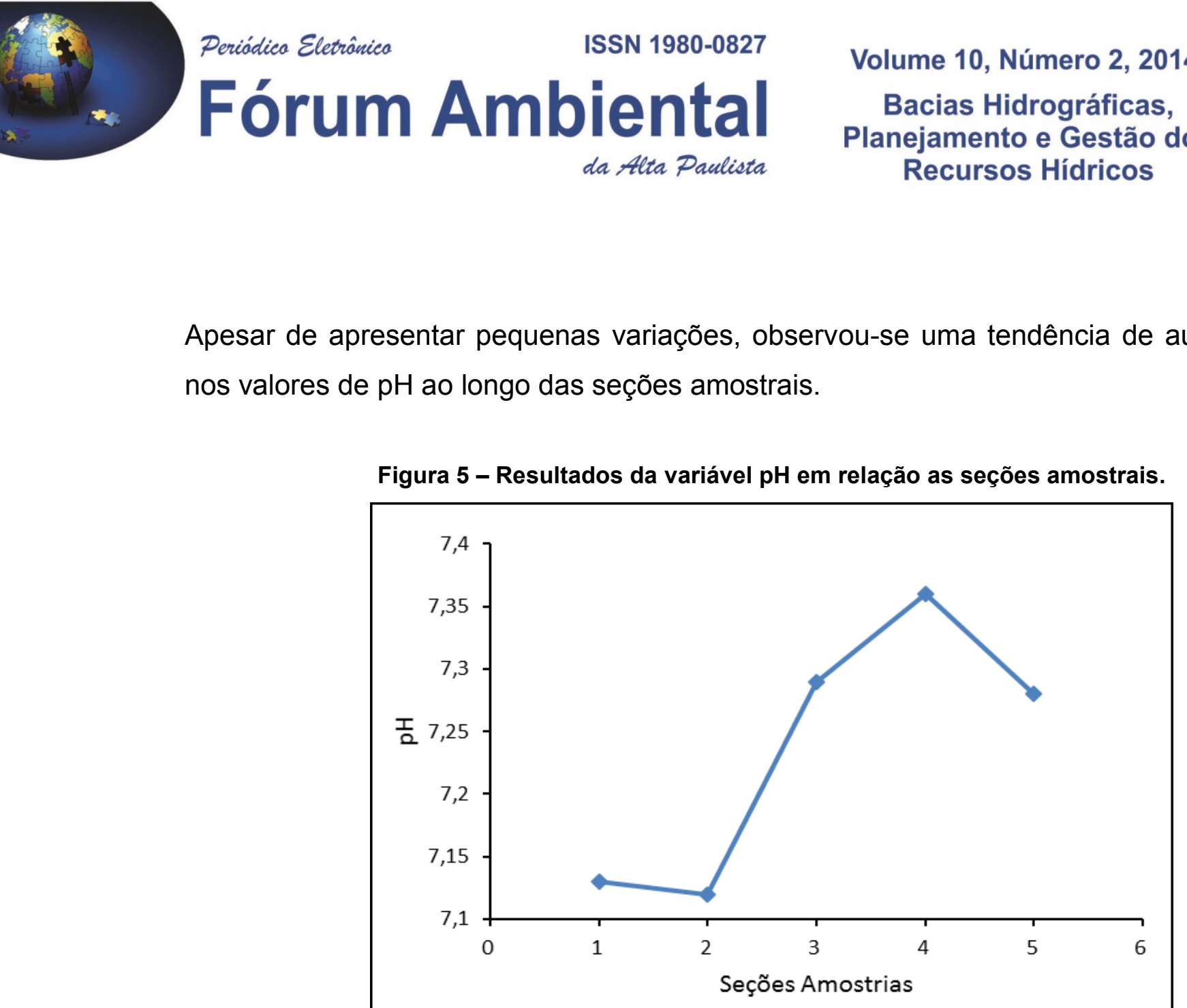

Apesar de apresentar pequenas variações, observou-se uma tendência de aumento nos valores de $\mathrm{pH}$ ao longo das seções amostrais.

Figura 5 - Resultados da variável pH em relação as seções amostrais.

Os resultados de condutividade elétrica estão apresentados na Figura 6 . Os íons responsáveis pelos valores de condutividade nas águas interiores são os chamados macronutrientes do solo como o cálcio, o potássio, o magnésio, o carbonato, o sulfato, o cloreto entre outros, enquanto que o nitrato, o nitrito e o ortofosfato têm pouca influência (Esteves, 1998).

A resolução CONAMA 357/05 não apresenta valores reguladores para a condutividade elétrica. Por outro lado, a condutividade mostrou-se com valores altos em relação ao recomendado pela Companhia de Tecnologia de Saneamento Ambiental (CETESB), órgão de controle e fiscalização do estado de São Paulo, que afirma que valores acima de $100 \mu \mathrm{S} / \mathrm{cm}$ indicam degradação. Um dos fatores associados a este quadro é a escassez de matas ciliares ao longo do curso d'água, pois, segundo Tundisi (1988), a presença de vegetação ciliar tem a função na redução dos valores deste parâmetro, já que a mesma exerce um poderoso efeito na absorção de íons dissolvidos. 
Figura 6 - Resultados da variável condutividade elétrica em relação as seções amostrais.

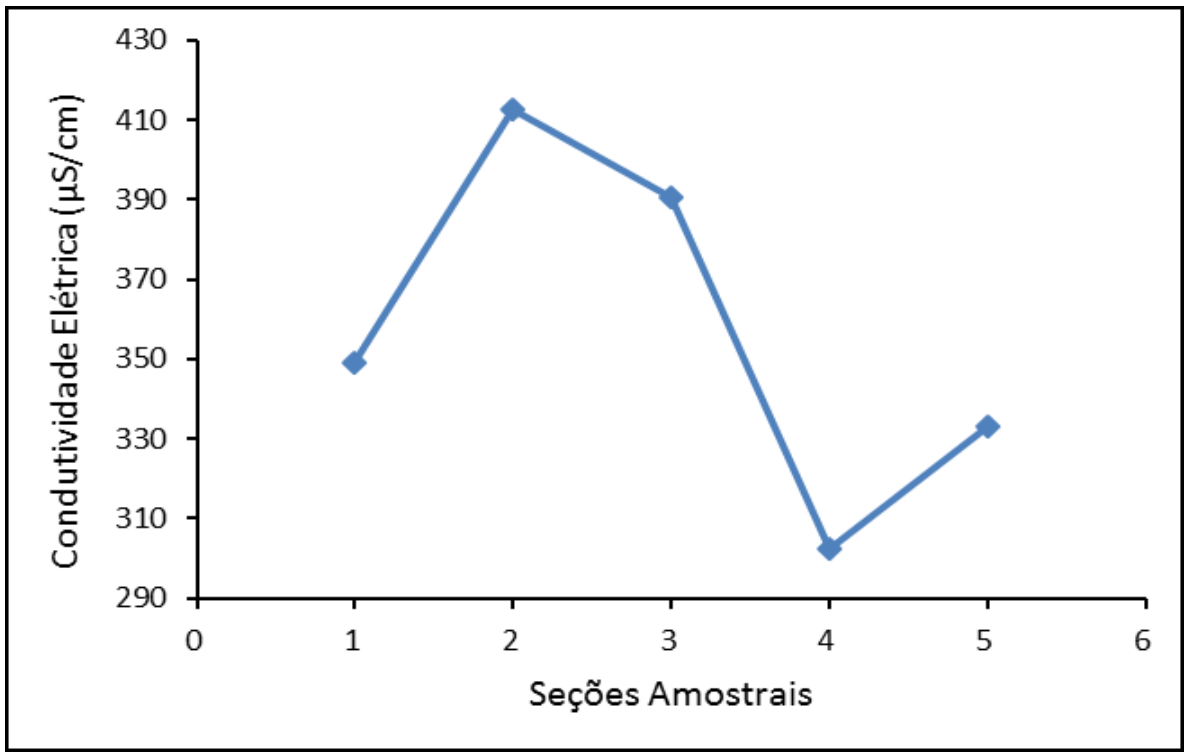

A turbidez é a medida da capacidade da água em dispersar a radiação solar. É expressa, entre outras unidades, por NTU (Nephelometric Turbidity Units) e sofre influência direta da presença de sólidos em suspensão, que impedem que o feixe de luz penetre na água, reduzindo a fotossíntese da vegetação submersa e algas (Tavares, 2005).

Neste sentido, o aumento da turbidez implica na redução da concentração de oxigênio dissolvido que é produzido pela fotossíntese. Assim, a turbidez influencia tanto na concentração de oxigênio quanto no pH da água.

Os valores de turbidez observados (Figura 7) mostraram-se bem baixos, o que pode ser relacionado a pouca presença de material em suspensão no córrego. A baixa quantidade de chuvas no mês de coleta também pode ter contribuído para os baixos valores de turbidez. 
Figura 7 - Resultados de Turbidez em relação as seções amostrais

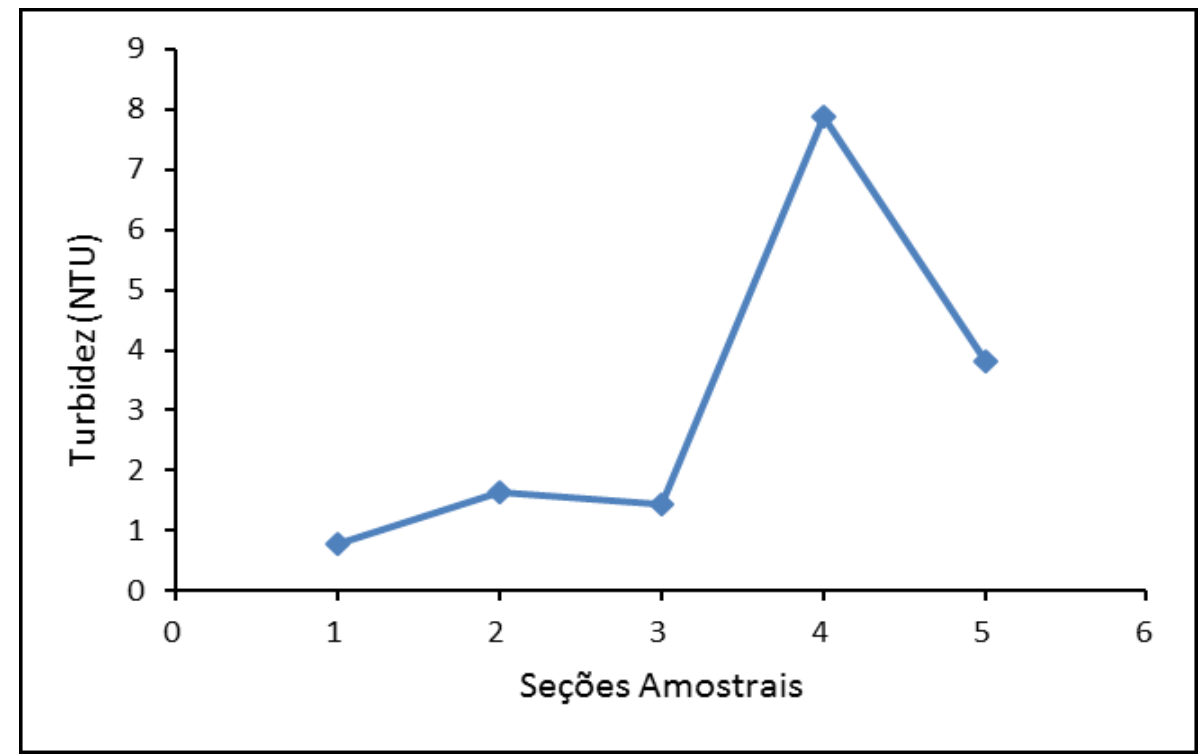

Os resultados de nitrato encontrados no córrego demonstraram valores superiores ao permitido pela resolução CONAMA 357/05, que é de $10 \mathrm{mg} / \mathrm{L}$ para córregos de classe 2. Isso demonstra poluição por nitrato e este representa um risco à saúde pública.

De acordo com a Figura 8, percebeu-se que as maiores concentrações estão próximas à nascente e a presença da malha urbana deve ser considerada, pois pode estar havendo lançamento de esgoto in natura no córrego. 
Figura 8 - Resultados da variável nitrato em relação às seções amostrais.

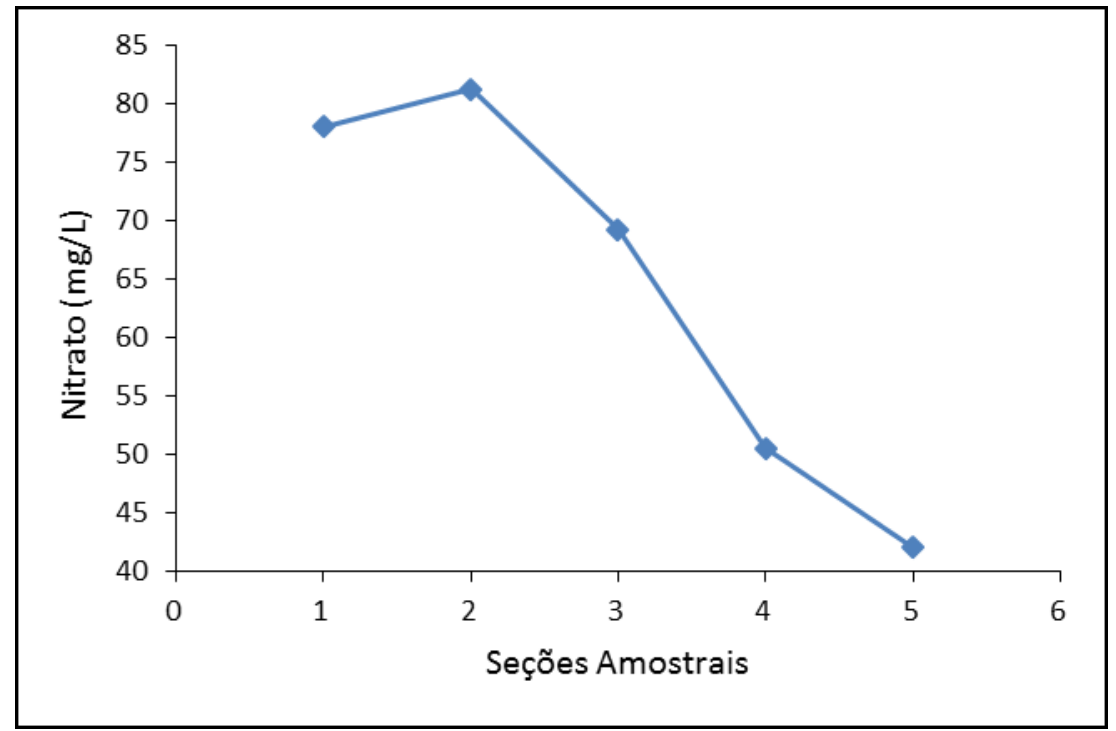

\section{CONCLUSÃO}

A presente pesquisa permitiu verificar o comportamento espacial de variáveis limnológicas, possibilitando compreender a dinâmica do corpo d'água.

Os valores das variáveis, condutividade elétrica e nitrato, em desacordo com a legislação ambiental, evidenciaram que a água do córrego dos Macacos não está adequada para seus usos preponderantes: a) ao abastecimento para consumo humano, após tratamento convencional; b) a proteção das comunidades aquáticas; c) a recreação de contato primário, tais como natação, esqui aquático e mergulho, conforme Resolução CONAMA n ${ }^{\circ} 274$, de 2000; d) a irrigação de hortaliças, plantas frutíferas e de parques, jardins, campos de esporte e lazer, com os quais o publico possa vir a ter contato direto; e e) a aquicultura e a atividade de pesca.

É notável que a presença humana esteja interferindo na qualidade do corpo d'água negativamente. Medidas mitigadoras, neste caso, devem estar relacionadas tanto à preservação do solo e da cobertura vegetal, quanto à conscientização ambiental da população local para que fontes pontuais e difusas de poluição sejam eliminadas. 


\title{
AGRADECIMENTO
}

\author{
À Fundação de Amparo à Pesquisa do Estado de São Paulo (FAPESP) pelo \\ apoio financeiro ( $n^{\circ}$ 2014/02875-7).
}

\section{REFERÊNCIAS}

ALVES, E. C. et. al. Avaliação da qualidade da água da bacia do rio Pirapó - Maringá, Estado do Paraná, por meio de parâmetros físicos, químicos e microbiológicos. Acta Scientiarum. Technology, v. 30 , n. 1, p. 39-48, 2008.

ANGELOCCl; L. R. \& VILLA NOVA, N. A. "Variações da Temperatura da Água de um Pequeno Lago Artificial ao longo de um ano em Piracicaba-SP", Sci. Agric., v. 52, n. 3, pp. 431-438. 1995.

BOULTON, A.J.; FINDLAY, S.; MARMONIER, P.; STANLEY, E.H.; VALLET, H.M. The functional significance of the hyporheic zone in streams and rivers. Annu. Rev. Ecol. Syst., 29:59-81. 1998.

ESTEVES, F. A. Fundamentos de Limnologia. 2a Ed. Rio de Janeiro: Interciência, 1998.

FIORUCCI, A.R. E BENEDETTI -FILHO, E. A importância do oxigênio dissolvido em ecossistemas aquáticos. Química Nova na Escola, n. 22, p. 10-16, 2005.

MADRUGA, Joana; RAO, Vladamudi Brahmananda; HADA, Kioshi. Relações entre temperatura e precipitação no Brasil. Disponível em: <http://www.cbmet.com/cbm-files/136671a0ee44a613435770f050c3e56438.pdf>. Acesso em: 15 set. 2014.

MAIER, M.H. Ecologia da bacia do rio Jacaré Pepira $\left(47^{\circ} 55^{\prime}-48^{\circ} 55^{\prime}\right.$ W; $22^{\circ} 30^{\prime}-2^{\circ} 55^{\prime}$ S - Brasil): qualidade da água do rio principal. Ciência e Cultura, 39(2): 164-185, 1987.

OLIVEIRA FILHO, A. T. et al. Estrutura fitossociológica e variáveis ambientais em um trecho da mata ciliar do córrego dos Vilas Boas, Reserva Biológica do Poço Bonito, Lavras (MG). Revista Brasileira de Botânica, v. 17, p. 67-85. 1994.

OLLI, G.; DARRACQ, A.; DESTOUNI, G. Field study of phosphorous transport and retention in drainage reaches. Journal of Hydrology, v. 365, n. 1, p. 46-55, 2009.

OWENS, L. B. Impacts of soil N management on the quality of surface and subsurface water. In: LAL, R.; STEWART, B. A. (Ed.). Soil processes and water quality: advances in soil science. Boca Raton Lewis Publishers. p. 17-162. 1994

ROCHA, R. R. de A. Limnologia Comparativa e Predativa de Rios e Lagoas da Planície de Inundação do Alto Rio Paraná (PR/MS - Brasil). 86f. Tese (Ecologia de Ambientes Aquáticos Continentais) - Universidade Estadual de Maringá - Maringá. 2003.

SCHNEIDER, Roselene Maria et al. Estudo da influência do uso e ocupação de solo na qualidade da água de dois córregos da Bacia hidrográfica do rio Pirapó. Acta Scientiarum.: Technology, Maringá, v. 33, n. 3, p.295-303, 2011. 
TAVARES, A.R. Monitoramento da qualidade das águas do rio Paraíba do Sul e diagnóstico de conservação. Dissertação de Mestrado, Instituto Tecnológico de Aeronáutica-ITA, São José dos Campos, São Paulo. 176pp, 2005

TUNDISI, J. G. Limnologia e Manejo de Represas. Vol. I. São Paulo: Universidade de São Paulo, Escola de Engenharia de são Carlos / CRHEA/ ACIESP, 506 p. 1988

TUNDISI, José Galizia; MATSUMURA, Takako. Limnologia. São Paulo: Oficina de Textos, 2008.

ZUIN V. G.; IORIATTI, M. C. S. e MATHEUS, C. E. O Emprego de Parâmetros Físicos e Químicos para a Avaliação da Qualidade de Águas Naturais: Uma Proposta para a Educação Química e Ambiental na Perspectiva CTSA. Química Nova na Escola, v. 31, n.1, p. 3-8, 2009.

ZUMACH, R. Enquadramento de curso de água Rio Itajaí- Açu e seus principais afluentes em Blumenau. Florianópolis, 2003. 124 f. Dissertação (Mestrado) - Programa de Pós-Graduação em Engenharia Ambiental. Universidade Federal de Santa Catarina, 2003. 